\title{
Testing the Mediating Role of Phubbing in the Relationship Between the Big Five Personality Traits and Satisfaction with Life
}

\author{
Özkan Çikrikci ${ }^{1} \cdot$ Mark D. Griffiths $^{2}$ (D) Evren Erzen $^{3}$
}

Published online: 31 July 2019

(C) The Author(s) 2019

\begin{abstract}
Phubbing refers to an individual giving more attention to their mobile phone when in face-toface communication with another individual. Research in the area of phubbing is relatively new and is often related to habitual mobile phone use. The aim of the present study was to explore the relationships between phubbing, the Big Five personality traits, and life satisfaction. The mediating role of phubbing in the relationship between personality traits and life satisfaction was also investigated. The sample comprised 292 university students (192 females [65.8\%] and 100 males [34.2\%]). The age of the university students in the study group ranged from 17 to 28 years and the mean age was 20.05 years $(\mathrm{SD}=2.33)$. Correlation analysis demonstrated that there were significant relationships between life satisfaction, phubbing, communication disturbances, and neuroticism. Phubbing was shown to have a nonsignificant relationship with life satisfaction. The study also examined the mediating role of communication disturbances in the relationship between neuroticism and life satisfaction. Neuroticism was shown to have a significant effect on communication disturbances, and communication disturbances had a significant effect on life satisfaction. Consequently, communication disturbances had a mediating role in the relationship between neuroticism and life satisfaction.
\end{abstract}

Keywords Phubbing $\cdot$ Communication disturbances $\cdot$ Smartphone obsession $\cdot$ Habitual smartphone use $\cdot$ Big Five personality traits $\cdot$ Life satisfaction

Mark D. Griffiths

mark.griffiths@ntu.ac.uk

Özkan Çikrikci

ozkanc61@ hotmail.com

Evren Erzen

evrenerzen@hotmail.com

Extended author information available on the last page of the article 
Life satisfaction is expressed as the sum of satisfaction perceptions that individuals have developed for their lives (Pavot and Diener 1993), and forms the cognitive dimension of the phenomenon of well-being (Diener 2000). Researchers have begun examining how individuals can be happier, while evaluating parameters that affect their life satisfaction (Chou and Edge 2012; Johnson and Acabchuk 2018; Myers and Diener 1995). It is known that personality traits are influential on both well-being and life satisfaction (Mueller et al. 2018; Sun et al. 2018). Nevertheless, the associations between personality traits and life satisfaction have not yet been investigated in relation to phubbing (i.e., "phone snubbing," in which individuals attend to messages on their smartphone during face-to-face conversations), a behavior that has become commonplace in contemporary society (Roberts and David 2016). Consequently, in the present study, the associations between personality traits, phubbing, and life satisfaction were explored, along with the mediating role of phubbing. The overall aim was to evaluate life satisfaction from a different perspective, which is considered as one of the indicators of wellbeing (Diener and Diener 1996).

\section{Life Satisfaction}

Life satisfaction is defined as the sense of satisfaction towards the whole of life (Diener and Diener 1996; Pavot and Diener 1993). Life satisfaction arises from subjective judgments of individuals. In this context, life satisfaction is defined as the broad evaluation of individuals' lives. In this evaluation process, individuals form standards that fit their own lifestyle and compare their situation in their own lives with these standards. Thus, there is a subjective assessment that is more effective than an assessment based on external factors (Pavot et al. 1991). For this reason, life satisfaction is a conscious cognitive process that individuals make to assess their lives in accordance with their own standards (Pavot and Diener 1993). In the context of conceptual inferences, life satisfaction can be defined as having gains that provide hedonic satisfaction in an individual's life. According to Çikrıkci (2016), life satisfaction is the cognitive appraisal of the distances between what individuals want to achieve and the hedonic gains they have.

\section{Personality Traits}

In personality research, the Five Factor Model is an important approach that has been widely agreed upon in explaining personality (Albuquerque et al. 2013). The constructs affecting the affective, cognitive, and behavioral functions of individuals are widely accepted and evaluated across five basic structures (Costa Jr and McCrae 1995; McCrae and Costa 2006; Somer and Goldberg 1999). Extraversion is associated with the nature and intensity of interpersonal relationships and is a trait where individuals enjoy being around other people (Albuquerque et al. 2013). Extravert individuals who are self-confident, and initiate and sustain relationships, are characterized by social, communicative, and joyful characteristics. Neuroticism, which functions against emotional coherence, comprises a susceptibility to anxiety and threats (Marshall et al. 2015). Openness is the most cognitively based of personality traits within the model and is associated with proactive experiences. Open individuals are defined as creative, intelligent, curious, and active individuals (McCrae and Costa 2006; Şimşek and Koydemir 2013). Agreeableness is characterized by constructive and healthy relationships 
with others around the individual. In other words, it is the evaluation of the person's interpersonal orientation between beliefs, conflict, and compliance observed in emotions and behaviors (Albuquerque et al. 2013). Individuals with a strong sense of conscientiousness are characterized as hardworking, determined, and responsible people who can control their impulses (Costa Jr. and McCrae 1992; McCrae and Costa 2006).

\section{Phubbing}

As noted above, phubbing refers to an individual giving more attention to their mobile phone while in face-to-face communication with another individual (Roberts and David 2016). Phubbing is therefore an antisocial behavior that has arisen due to the increasingly habitual use of smartphones (Balta et al. 2018). The fact that smartphones have computer and Wi-Fi capabilities suggests that phubbing is potentially multi-dimensional in nature. More specifically, phubbing might occur as a result of habitual smartphone use (in general), as well as specific activities that can be carried out on a smartphone (such as social media use, gaming, and gambling). It is noted that phubbing appears to becoming increasingly prevalent and that the activity might have potentially negative effects among some smartphone users (Balta et al. 2018; Montenegro et al. 2016).

The widespread use of mobile phones and (more recently Wi-Fi enabled) smartphones makes them an increasingly indispensable part of human life. Mobile phones that were primarily focused on speech only have turned into mobile devices that can do almost anything a computer can do. Dependence on developing technology (Turel et al. 2011) has gradually turned into problematic phone use (Bianchi and Phillips 2005; Billieux et al. 2008) and has been described as an addiction by some scholars (Park 2005). Phubbing is a relatively new concept in the literature but is inextricably associated with smartphone use. The antisocial nature of phubbing has led to increased research on the phenomenon, particularly the more detrimental effects that impact on an individual's social communication with others (e.g., Chotpitayasunondh and Douglas 2016; Nazir and Pișkin 2016; Roberts and David 2017; Ugur and Koc 2015).

Phubbing has the potential to be a habitual behavior (Balta et al. 2018). Theoretically, habitual phubbing could be associated with internet addiction (Weinstein and Lejoyeux 2010), smartphone addiction (Hussain et al. 2017), mobile gaming addiction (Balakrishnan and Griffiths 2018), text message addiction (Hassanzadeh and Rezaei 2011), and social media addiction (Kuss and Griffiths 2017). In extreme cases, phubbing may lead to problems in communication with other people and therefore may share lack of face-to-face communication overlaps with internet addiction (Griffiths 2000; Kuss et al. 2014). For a minority of individuals, they may become more interested in relationships in the virtual world than in the realworld relationships and may lead the individual to isolation and loneliness. Such consequences have been associated with internet addiction (Kuss et al. 2014; Ostovar et al. 2016) and may also be a consequence of extreme phubbing.

\section{The Present Study}

Personality traits are important determinants of life satisfaction (Schimmack et al. 2002). For instance, there is significant positive relationship between extraversion, agreeableness, 
conscientiousness, and life satisfaction, whereas there is a significant negative correlation between neuroticism and life satisfaction (DeNeve and Cooper 1998; McCrae and Costa Jr. 1991; Weber and Huebner 2015). The constructive atmosphere created by extraverted, agreeable, and conscientious individuals raises life satisfaction by increasing positive emotions. Similarly, the destructive cognitive and affective responses of neurotic individuals can affect their lives negatively (Lucas and Fujita 2000).

In the present study, the effect of phubbing on life satisfaction was investigated. Phubbing can be regarded as a cognitive, emotional, and behavioral reflection of the structures that are later integrated into human life, as mentioned above. There are few studies concerning phubbing, simply because it is a relatively new concept. However, there are no studies that have investigated phubbing in terms of personality traits and life satisfaction. The determination of the effects of phubbing on life satisfaction represents the originality and novelty of the present research. Given that phubbing may restrict face-to-face social interactions, it may also affect the well-being of such individuals and their life satisfaction.

Consequently, the present study investigated how phubbing is associated with personality traits and life satisfaction. It is hypothesized that phubbing - which prevents individuals from being active in social settings and interacting with other people - may be affected by personality traits. It is assumed that the effect of personality traits on life satisfaction can be reduced or eliminated when phubbing is included in such a model. Consequently, phubbing is assessed as a mediating variable. The primary aim of the present was study was to evaluate the mediating role of phubbing in relation to the Big Five personality traits and life satisfaction.

\section{Methods}

\section{Research Design}

The present study was conducted utilizing a correlational model. In this way, the relationships between behavior patterns and variables that define behavior can be determined (Cohen et al. 2007; McMillan and Schumacher 2006). In accordance with the nature of correlational research, the aim here is to define the role of a mediating variable (phubbing) in the relationship between independent variables (personality traits) on the dependent variable (life satisfaction).

\section{Participants}

The sample comprised 292 Turkish university students (192 females [65.8\%] and 100 males [34.2\%]). The age of the university students ranged from 17 to 28 years with a mean age of 20.05 years $(\mathrm{SD}=2.33)$. Almost all of the participants used smartphones $(N=287 ; 98.3 \%)$. Among the descriptive findings related to the sample, the duration of daily internet usage was assessed. Consequently, 21 participants spent $1 \mathrm{~h}$ a day on the internet (7.2\%), 140 participants spent $1-3 \mathrm{~h}$ a day on the internet (47.9\%), 108 participants spent $4-5 \mathrm{~h}$ a day on the internet (37\%), and 23 participants spent more than $5 \mathrm{~h}$ a day on the internet (7.9\%). Finally, the primary purpose of university students' use of the internet was also assessed. Consequently, the participants primarily used the internet for communication $(n=109 ; 37.3 \%)$, entertainment $(n=89 ; 30.5 \%)$, information and news $(n=75 ; 25.7 \%)$, and research purposes $(n=19 ; 6.5 \%)$. 


\section{Procedure and Ethical Approval}

The first author's university ethics committee approved data collection, and the study was conducted in accordance with the 1975 Helsinki Declaration. Signed consent forms were attained from each student. The research team administered a "paper and pencil" survey to psychology students in their lectures. Participation was voluntary and participants were assured that all data were anonymous and confidential.

\section{Measures}

Ten-Item Personality Inventory The Ten-Item Personality Inventory (TIPI) was developed by Gosling, Rentfrow, and Swann (2003) to assess personality traits. The inventory utilizes a Likert-type scale with a 5-point evaluation. The TIPI comprises 10 items assessing the Big Five personality domains (extraversion, openness, agreeableness, conscientiousness, and neuroticism). The validity and reliability study of the Turkish form was performed by Atak (2013). The reliability coefficients of subscales of the Turkish version of the inventory vary between 0.81 and 0.86 . The structural validity of TIPI was examined by means of confirmatory factor analysis (CFA). Additionally, the CFA revealed sufficient fit indices (AGFI $=0.92, \mathrm{CFI}=0.93$, and RMSEA $=0.03$ ) to the data (Atak 2013). For the current study, Cronbach's alphas of extraversion, agreeableness, openness, conscientiousness, and neuroticism were $0.73,0.69$, $0.70,0.72,0.71$, respectively.

Phubbing Scale The Phubbing Scale was developed by Karadağ et al. (2015) in order to assess phubbing behavior. The PS utilizes a 5-point Likert-type scale comprising 10 items. Communication disturbance $(\alpha=0.87)$ and phone obsession $(\alpha=0.85)$ are the two subfactors. For the present study, the internal validities of sub-factors of PS were good $\left(\alpha_{\text {Communication disturbance }}=0.77, \alpha_{\text {phone obsession }}=0.74\right)$.

Satisfaction with Life Scale The Satisfaction With Life Scale (SWLS) was developed by Diener et al. (1985) and utilizes a 7-point Likert-type scale to determine perceived life satisfaction of individuals. The validity and reliability study of the Turkish version of the scale was conducted by Yetim (1991). The reliability of the SWLS was examined with the internal consistency coefficient, and the result was that the instrument was reliable $(\alpha=0.86)$. Yetim (2003) determined the test-retest reliability of the Turkish version of the SWLS as 0.73. In the present study, the Cronbach's alpha for SWLS was high $(\alpha=0.80)$.

\section{Analytical Approach}

Prior to statistical analysis, the data needed to be organized and various statistical assumptions had to be examined. The assumptions needing to be examined included missing values, extreme values, normal distribution, and linearity (Field 2013). Missing value analysis was performed first in this study, and no missing data associated with measurements in the dataset were determined. At extreme value analysis, scores for variables in the dataset were converted into standard $z$ scores in order to determine the extent to which data deviated from the mean. In the study, the scores obtained from continuous variables were converted to $z$ scores and the scores obtained were found to be in the range of -3 and +3 (Field 2013). Skew and kurtosis 
values were examined during assessment of normal distribution (Table 1). Distortion values within the skew and kurtosis values regarded as criteria in the relevant literature $(-1.5$ and + 1.5) indicated no deviation from normal distribution (Tabachnick and Fidell 2007).

The theory of mediation is one of the theories used in examining relationships of cause and effect. In addition, mediation analysis is used as a causal model investigating processes affecting the emergence of cause and effect relations (Rose et al. 2004). Baron and Kenny (1986) proposed preliminary statements regarding testing for mediation. However, in this model, the effect of the mediator variable expressed as $\mathrm{c}^{-\mathrm{c}^{1}}$ or $a b$ on the dependent variable cannot be evaluated. Therefore, Baron and Kenny (1986) suggest that the Sobel test is practical to use. In order for the Sobel test to be functional, normal distribution assumptions need to be met. In addition, large samples have to be studied in order to be able to calculate the indirect effect of the mediator variable $(a b)$. At this stage, the examination of confidence intervals using bootstrapping is recommended (Preacher and Hayes 2008). In this study, in addition to bootstrapping-based confidence intervals $(N=10,000)$, the $\kappa^{2}$ and $P_{M}$ values were also examined as recommended by Preacher and Kelley (2011). Data analysis was performed using SPSS 22.0 software. Analysis was performed by downloading the PROCESS macro (Simple Mediation Model 4) developed in order to be able to test mediation based on bootstrapping (Preacher and Hayes 2004) (Fig. 1).

\section{Results}

\section{Preliminary Analysis}

As a result of correlation analysis, there were significant relationships between life satisfaction and phubbing $(r=-0.15, p<0.01 ; 95 \%$ CI $[-0.27,-0.03])$, communication disturbances $(r=-0.17, p<0.01 ; 95 \%$ CI $[-0.28,-0.04])$, and neuroticism $(r=-0.14, p<0.01 ; 95 \% \mathrm{CI}$ $[-0.24,-0.02])$. As shown in Table 2 , there were no significant relationships between life satisfaction and phubbing, phone obsession, extraversion, openness, consciousness, and agreeableness. Therefore, the mediating roles of phubbing and communication disturbance in relation to neuroticism and life satisfaction were analyzed in the mediation analysis (Fig. 2).

Table 1 Skewness and kurtosis coefficients for the measures

\begin{tabular}{|c|c|c|c|c|c|c|c|c|c|}
\hline & \multirow[t]{2}{*}{$N$} & \multirow[t]{2}{*}{ Min. } & \multirow[t]{2}{*}{ Max. } & \multirow[t]{2}{*}{$M$} & \multirow[t]{2}{*}{$\mathrm{SD}$} & \multicolumn{2}{|c|}{ Skewness } & \multicolumn{2}{|c|}{ Kurtosis } \\
\hline & & & & & & Value & Error & Value & Error \\
\hline LF & 292 & 5.00 & 33.00 & 19.41 & 6.33 & -0.20 & 0.14 & -0.70 & 0.28 \\
\hline $\mathrm{P}$ & 292 & 10.00 & 50.00 & 28.26 & 7.46 & -0.20 & 0.14 & -0.39 & 0.28 \\
\hline $\mathrm{CD}$ & 292 & 5.00 & 25.00 & 12.81 & 4.08 & -0.01 & 0.14 & -0.64 & 0.28 \\
\hline $\mathrm{PO}$ & 292 & 5.00 & 25.00 & 15.45 & 4.32 & -0.28 & 0.14 & -0.45 & 0.28 \\
\hline $\mathrm{E}$ & 288 & 2.00 & 14.00 & 8.47 & 1.99 & -0.05 & 0.14 & 0.29 & 0.28 \\
\hline $\mathrm{O}$ & 287 & 2.00 & 14.00 & 7.49 & 2.38 & 0.06 & 0.14 & -0.07 & 0.28 \\
\hline $\mathrm{N}$ & 292 & 2.00 & 14.00 & 9.28 & 2.42 & -0.23 & 0.14 & 0.05 & 0.28 \\
\hline $\mathrm{C}$ & 285 & 2.00 & 14.00 & 8.34 & 2.17 & 0.07 & 0.14 & 0.62 & 0.28 \\
\hline A & 287 & 2.00 & 14.00 & 8.52 & 2.17 & -0.07 & 0.14 & 0.06 & 0.28 \\
\hline
\end{tabular}

$L F$ life satisfaction, $P$ phubbing, $C D$ communication disturbances, $P O$ phone obsession, $E$ extraversion, $O$ openness, $N$ neuroticism, $C$ conscientiousness, $A$ agreeableness 

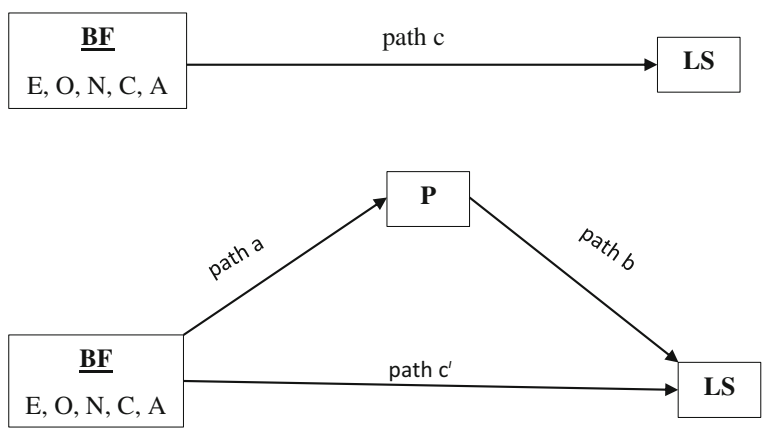

BF: Big Five, E: Extraversion, O: Openness, N: Neuroticism, C: Conscientiousness, A: Agreeableness, P: Phubbing, LS: Life Satisfaction

Fig. 1 The mediation model. BF Big Five, E extraversion, O openness, N neuroticism, C conscientiousness, A agreeableness, P phubbing, LS life satisfaction

\section{Mediation Analysis}

The mediating role of phubbing in relation to neuroticism and life satisfaction was assessed in the initial phase of mediation analysis. Due to the fact that the predictive role of phubbing on life satisfaction was not significant, the assumptions of mediation analysis were not found. $\left(\beta=-0.10, \mathrm{SE}=0.05 ; t_{(289)}=1.89, p>0.05,95 \%\right.$ CI $\left.[-0.21,0.01]\right)$. Consequently, the mediating role of phubbing in relation to neuroticism and life satisfaction could not be evaluated. In the next phase, the mediating role of communication disturbance was investigated. As seen in the unstandardized regression coefficients, it was found that neuroticism had a significant effect on communication disturbance $\left(\beta=0.32, \mathrm{SE}=0.10 ; t_{(290)}=3.21, p<0.01\right.$, $95 \%$ CI $[0.12,0.52]$, path a), and communication disturbance had a significant effect on life satisfaction $\left(\beta=-0.22, \mathrm{SE}=0.09, t_{(289)}=2.33, p<0.05,95 \% \mathrm{CI}[-0.41,-0.04]\right.$, path $\left.\mathrm{b}\right)$. The fact that both path a and path $b$ were significant, the confidence interval based on the bootstrapping method was applied in mediation analysis (Preacher and Hayes 2008). In the present study, communication disturbance had a mediating role in the relationship between neuroticism and life satisfaction $\left(a b=-0.07, \mathrm{SE}=0.04,95 \% \mathrm{CI}[-0.17,-0.02] ; \kappa^{2}=0.03\right.$, $\mathrm{SE}=0.14,95 \%$ CI $[0.01,0.07])$.

Table 2 Correlations among variables

\begin{tabular}{|c|c|c|c|c|c|c|c|c|c|c|c|}
\hline & $M$ & SD & 1 & 2 & 3 & 4 & 5 & 6 & 7 & 8 & 9 \\
\hline 1.LS & 19.41 & 6.33 & 1 & & & & & & & & \\
\hline 2. $\mathrm{P}$ & 28.26 & 7.46 & $-0.15^{* *}$ & 1 & & & & & & & \\
\hline 3. $\mathrm{CD}$ & 12.81 & 4.08 & $-0.17 * *$ & $0.86^{* *}$ & 1 & & & & & & \\
\hline 4. $\mathrm{PO}$ & 15.45 & 4.32 & -0.08 & $0.87 * *$ & $0.49 * *$ & 1 & & & & & \\
\hline 5. E & 8.47 & 1.99 & -0.02 & 0.05 & 0.02 & 0.06 & 1 & & & & \\
\hline 6. $\mathrm{O}$ & 7.49 & 2.38 & -0.04 & 0.10 & 0.04 & $0.12 *$ & $0.24 * *$ & 1 & & & \\
\hline 7. $\mathrm{N}$ & 9.28 & 2.42 & $-0.14 * *$ & 0.08 & $0.13 *$ & 0.02 & $0.19 * *$ & $0.25 * *$ & 1 & & \\
\hline 8. $\mathrm{C}$ & 8.34 & 2.17 & -0.05 & 0.07 & 0.04 & 0.08 & $0.22 * *$ & $0.19 * *$ & $0.18^{* *}$ & 1 & \\
\hline 9. A & 8.52 & 2.17 & -0.06 & -0.01 & -0.01 & 0.01 & 0.10 & 0.06 & 0.10 & $0.11 *$ & 1 \\
\hline
\end{tabular}

$N=353, * * p<0.01 ; L F$ life satisfaction, $P$ phubbing, $C D$ communication disturbances, $P O$ phone obsession, $E$ extraversion, $O$ openness, $N$ neuroticism, $C$ conscientiousness, $A$ agreeableness 




Fig. 2 The mediation role of communication disturbances. N neuroticism, CD communication disturbances, LS life satisfaction

When communication disturbance was included to the mediation model, it was found that communication disturbance had a full mediating role because the association between neuroticism and life satisfaction was not significant $\left(\beta=-0.28, \mathrm{SE}=0.15, t_{(289)}=1.84, p>0.05\right.$, 95\% CI $[-0.59,0.02]$, path $\left.\mathrm{c}^{2}\right)$. Additionally, it was found that communication disturbance explained a significant part of the total effect on life satisfaction $\left(P_{M}=0.20,95 \%\right.$ CI $[0.03$, 1.30]) (Table 3).

\section{Discussion}

Phubbing has become an increasingly commonplace behavior yet, to date, little research has been carried out. Furthermore, no previous study has ever examined the relationship between life satisfaction and phubbing, which in the present research was considered as a mediating variable. Many studies have shown that there is a significant relationship between personality traits and life satisfaction (Zhang and He 2010; Nishimura and Suzuki 2016; Magee et al. 2013; Joshanloo and Afshari 2011; Zhang and Howell 2011). The primary purpose of the present study was to examine the relationship between personality traits, life satisfaction, and phubbing. In addition to examining the relationships between the variables studied in the study, the mediating role of phubbing in the relationship between personality traits and life satisfaction was assessed. The findings of the present study showed that only neuroticism was associated with life satisfaction. It has previously been reported that the lives of neurotic individuals experiencing emotional inconsistency are adversely affected (Lucas and Fujita 2000). Neurotic tendencies exhibited by the individual alongside social experiences may increase the negative affect (Bredemeier et al. 2011; Suls et al. 1998). It is thought that the negative cognitive and emotional reactions of neurotic individuals may negatively affect life satisfaction. Kuppens et al. (2008) emphasized the destructive effects of this negative affective process on life satisfaction.

Table 3 Results for mediation analysis

\begin{tabular}{|c|c|c|c|c|c|c|c|c|c|c|c|c|}
\hline \multirow[t]{2}{*}{$a b$} & \multicolumn{2}{|c|}{$95 \% \mathrm{CI}$} & \multirow[t]{2}{*}{$a$} & \multirow[t]{2}{*}{$b$} & \multirow[t]{2}{*}{$c$} & \multirow[t]{2}{*}{$c^{l}$} & \multirow[t]{2}{*}{$P_{M}$} & \multicolumn{2}{|c|}{$95 \% \mathrm{CI}$} & \multirow[t]{2}{*}{$\kappa^{2}$} & \multicolumn{2}{|c|}{$95 \% \mathrm{CI}$} \\
\hline & LL & UL & & & & & & $\mathrm{LL}$ & UL & & LL & UL \\
\hline-0.07 & -0.17 & -0.02 & $0.32 * *$ & $-0.22 *$ & $-0.35^{*}$ & -0.28 & 0.20 & 0.03 & 1.30 & 0.03 & 0.01 & 0.07 \\
\hline
\end{tabular}

$a b=$ estimated indirect effect. Confidence intervals generated by means of bias corrected and bootstrapping $(N=$ $10,000)$ 
The attitudes of neurotic individuals tend to be non-functional in the face of the tasks that they encounter in the developmental process. Neurotic individuals frequently use incompatible coping strategies and find themselves in a cycle of emotional inconsistency (Albuquerque et al. 2013). Neurotic individuals may not achieve the gains they desire in life because of these negative emotions and emotional inconsistencies. Life satisfaction is conceptualized by the distance between the individual and the hedonic gains (Çikrıkci 2016). Although no significant association was found between the other four of the Big Five personality traits (i.e., extraversion, openness, consciousness, and agreeableness) and life satisfaction in the present study, other studies have indicated an association between life satisfaction and extraversion, openness, consciousness, and agreeableness (DeNeve and Cooper 1998; Grevenstein and Bluemke 2015; Joshanloo and Afshari 2011). Consequently, the results in the present study are inconsistent with the literature. This may be due to the different sample and sampling methods used and/or due to cultural differences given that the present study only comprised psychology students.

Another finding of the present study was that communication disturbance had a mediating role between neuroticism and life satisfaction. The mediator variable demonstrated that communication disturbance had the mechanism by which neuroticism can bring about changes in life satisfaction (i.e., communication disturbance had a potential in the role of neuroticism on life satisfaction). This finding indicates neuroticism with communication disturbance (mediator variable) may have diverse effects on life satisfaction. Moreover, the current mediation role may be interpreted as showing that the increase in the level of neuroticism leads to an increase in the level of communication disturbance which leads to a decrease in life satisfaction. In the present study, it appears that neuroticism negatively affects the lifestyle cognitive appraisals of individuals by laying the groundwork for communication disturbance.

Communication disturbance is the inability to use the language appropriate when social interaction occurs, and eventually results in problems concerning communication skills. Neurotic individuals who are anxious, angry, anxious, and/or insecure in daily life are thought to be unable to maintain their social relationships in a healthy way (Gonda et al. 2009). Consequently, neurotic individuals may use the smartphone as a way of interacting rather than establishing direct face-to-face relationships. Furthermore, neurotic individuals with an unconventional approach to social relationships may be more likely to encounter negative life events (Weber and Huebner 2015), which may weaken perceptions of life satisfaction.

As noted above, there is no previous study examining the role of phubbing and communication disturbance on life satisfaction in the literature. However, the present study's findings emphasize the relationship between life satisfaction, phubbing, and communication disturbance. Previous studies have shown that there is a significant relationship between gaming addiction, smartphone addiction, and well-being (Myrseth et al. 2017; Samaha and Hawi 2016; Song et al. 2018). The mediating role of communication disturbance identified in the present study could be interpreted as an indication of the cumulative interaction of the expressed dimensions. Unlike other personality traits, neurotic individuals' imbalances in social situations may lead to phubbing, as a way of overcoming these imbalance (Chotpitayasunondh and Douglas 2016). Phubbing is regarded as a disrespectful behavior and can damage social relationships in real life (Karadağ et al. 2015). Consequently, the individual is unable to achieve the desired gains in social relationships because of phubbing. In other words, phubbing in neurotic individuals may lead to an increase in distance between the hedonic wishes and their gains for social lives. Overall, this may lead to a decrease in life satisfaction. 


\section{Limitations, Recommendations, and Conclusions}

The present study is not without its limitations. The most notable limitation is related to potential generalization of the study. The sample size was modest, biased towards females, self-report, and contained only Turkish university students studying psychology. It is recommended that in order that the results to be generalized to other populations, future research should use bigger representative sample sizes, more equally distributed gender samples, and individuals from other countries and cultures. Also, because the present study was crosssectional and correlational, the results cannot provide any causal assumptions. In future studies, longitudinal studies are needed to explore causal associations among all the variables in the present study.

Despite its limitations, the findings of present study emphasized new associations in exploring life satisfaction among university students in terms of personality traits and phubbing. Additionally, the present study is the first to examine the mediating role of phubbing in the associations between personality traits and life satisfaction. The present study also provided empirical evidence that neuroticism and communication disturbance are negatively associated with life satisfaction, and that communication disturbance fully mediates the relationship of neuroticism with life satisfaction. More specifically, communication disturbance significantly influences life satisfaction among university students.

Funding The present research was supported by the Ordu University Scientific Research Coordinator (Research Project No: AR-1619).

\section{Compliance with Ethical Standards}

Conflict of Interest The authors declare that they have no conflicts of interest.

Ethical Approval All procedures performed in studies involving human participants were in accordance with the ethical standards of the institutional research committee and with the 1964 Helsinki declaration and its later amendments or comparable ethical standards. Additionally, the local ethical approval was obtained by Ethics Committee of Social and Human Sciences at Ordu University.

Open Access This article is distributed under the terms of the Creative Commons Attribution 4.0 International License (http://creativecommons.org/licenses/by/4.0/), which permits unrestricted use, distribution, and reproduction in any medium, provided you give appropriate credit to the original author(s) and the source, provide a link to the Creative Commons license, and indicate if changes were made.

\section{References}

Albuquerque, I., de Lima, M. P., Matos, M., \& Figueiredo, C. (2013). The interplay among levels of personality: The mediator effect of personal projects between the big five and subjective well-being. Journal of Happiness Studies, 14, 235-250.

Atak, H. (2013). The Turkish adaptation of the Ten-Item Personality Inventory. Archives of Neuropsychiatry, 50, 312-319.

Balakrishnan, J., \& Griffiths, M. D. (2018). Loyalty towards online games, gaming addiction, and purchase intention towards online mobile game features. Computers in Human Behavior, 87, 238-246.

Balta, S., Kircaburun, K., \& Griffiths, M. D. (2018). Neuroticism, trait-fear of missing out, and phubbing: The mediating role of state-fear of missing out and problematic Instagram use. International Journal of Mental Health and Addiction. https://doi.org/10.1007/s11469-018-9959-8. 
Baron, R. M., \& Kenny, D. A. (1986). The moderator-mediator variable distinction in social psychological research: Conceptual, strategic, and statistical considerations. Journal of Personality and Social Psychology, 51, 1173-1182.

Bianchi, A., \& Phillips, J. G. (2005). Psychological predictors of problem mobile phone use. Cyber Psychology and Behavior, 8, 39-51.

Billieux, J., Van der Linden, M., \& Rochat, L. (2008). The role of impulsivity in actual and problematic use of the mobile phone. Applied Cognitive Psychology, 22, 1195-1210.

Bredemeier, K., Berenbaum, H., Most, S. B., \& Simons, D. J. (2011). Links between neuroticism, emotional distress, and disengaging attention: Evidence from a single-target RSVP task. Cognition and Emotion, 25(8), 1510-1519.

Chotpitayasunondh, V., \& Douglas, K. M. (2016). How "phubbing" becomes the norm: the antecedents and consequences of snubbing via smartphone. Computers in Human Behavior, 63, 9-18.

Chou, H. T. G., \& Edge, N. (2012). "They are happier and having better lives than I am": the impact of using Facebook on perceptions of others' lives. Cyberpsychology, Behavior and Social Networking, 15, 117-121.

Çikrıkci, Ö. (2016). The effect of internet use on well-being: meta-analysis. Computers in Human Behavior, 65, 560-566.

Cohen, L., Manion, L., \& Morrison, K. (2007). Research methods in education (6th ed.). New York: Routledge Falmer.

Costa, P. T., Jr., \& McCrae, R. R. (1995). Domains and facets: Hierarchical personality assessment using the Revised NEO Personality Inventory. Journal of Personality Assessment, 64, 21-50.

Costa, P. T., Jr., \& McCrae, R. R. (1992). Revised NEO personality inventory (NEO-PI-R) and NEO five factor inventory (NEO-FFI). Odessa: Psychological Assessment Resources, Inc..

DeNeve, K. M., \& Cooper, H. (1998). The happy personality: A meta-analysis of 137 personality traits and subjective well-being. Psychological Bulletin, 124, 197-229.

Diener, E. (2000). Subjective well-being: The science of happiness and a proposal for a National Index. American Psychologist, 55, $34-43$.

Diener, E., \& Diener, C. (1996). Most people are happy. Psychological Science, 7, 181-185.

Diener, E. D., Emmons, R. A., Larsen, R. J., \& Griffin, S. (1985). The satisfaction with life scale. Journal of Personality Assessment, 49, 71-75.

Field, A. (2013). Discovering statistics using IBM SPSS (4th ed.). London: Sage.

Gonda, X., Fountoulakis, K. N., Juhasz, G., Rihmer, Z., Lazary, J., Laszik, A., Akiskal, H. S., \& Bagdy, G. (2009). Association of the s allele of the 5-HTTLPR with neuroticism-related traits and temperaments in a psychiatrically healthy population. European Archives of Psychiatry and Clinical Neuroscience, 259, 106113.

Gosling, S. D., Rentfrow, P. J., \& Swann Jr, W. B. (2003). A very brief measure of the Big-Five personality domains. Journal of Research in Personality, 37(6), 504-528.

Grevenstein, D., \& Bluemke, M. (2015). Can the Big Five explain the criterion validity of Sense of Coherence for mental health, life satisfaction, and personal distress? Personality and Individual Differences, 77, 106111.

Griffiths, M. (2000). Does Internet and computer 'addiction' exist? Some case study evidence. CyberPsychology and Behavior, 3, 211-218.

Hassanzadeh, R., \& Rezaei, A. (2011). Effect of sex, course and age on SMS addiction in students. Middle-East Journal of Scientific Research, 10, 619-625.

Hussain, Z., Griffiths, M. D., \& Sheffield, D. (2017). An investigation in to problematic smartphone use: The role of narcissism, anxiety, and personality factors. Journal of Behavioral Addictions, 6, 378-386.

Johnson, B. T., \& Acabchuk, R. L. (2018). What are the keys to a longer, happier life? Answers from five decades of health psychology research. Social Science \& Medicine, 196, 218-226.

Joshanloo, M., \& Afshari, S. (2011). Big five personality traits and self-esteem as predictors of life satisfaction in Iranian Muslim University students. Journal of Happiness Studies, 12, 105-113.

Karadağ, E., Tosuntaș, Ș. B., Erzen, E., Duru, P., Bostan, N., Șahin, B. M., Çulha, İ., \& Babadağ, B. (2015). Determinants of phubbing, which is the sum of many virtual addictions: A structural equation model. Journal of Behavioral Addictions, 4, 60-74.

Kuppens, P., Realo, A., \& Diener, E. (2008). The role of positive and negative emotions in life satisfaction judgment across nations. Journal of Personality and Social Psychology, 95, 66-75.

Kuss, D. J., \& Griffiths, M. D. (2017). Social networking sites and addiction: Ten lessons learned. International Journal of Environmental Research and Public Health, 14, 311.

Kuss, D. J., Griffiths, M. D., Karila, L., \& Billieux, J. (2014). Internet addiction: A systematic review of epidemiological research for the last decade. Current Pharmaceutical Design, 20, 4026-4052.

Lucas, R. E., \& Fujita, F. (2000). Factors influencing the relation between extraversion and pleasant affect. Journal of Personality and Social Psychology, 79, 1039-1056. 
Magee, C. A., Miller, L. M., \& Heaven, P. C. (2013). Personality trait change and life satisfaction in adults: The roles of age and hedonic balance. Personality and Individual Differences, 55, 694-698.

Marshall, T. C., Lefringhausen, K., \& Ferenczi, N. (2015). The Big Five, self-esteem, and narcissism as predictors of the topics people write about in Facebook status updates. Personality and Individual Differences, 85, 35-40.

McCrae, R. R., \& Costa, P. T. (2006). Personality in adulthood, a five-factor theory perspective (2nd ed.). New York: Guilford Press.

McCrae, R. R., \& Costa, P. T., Jr. (1991). Adding Liebe und Arbeit: The full five-factor model and well-being. Personality and Social Psychology Bulletin, 17, 227-232.

McMillan, J. H., \& Schumacher, S. (2006). Research in education: Evidence-based inquiry (6th ed.). New York: Pearson.

Montenegro, J. A., \& Torres, J. L. (2016). Consumer preferences and implicit prices of smartphone characteristics. Working Papers 2016-04, Universidad de Málaga, Department of Economic Theory, Málaga Economic Theory Research Center

Mueller, S., Wagner, J., Wagner, G. G., Ram, N., \& Gerstorf, D. (2018). How far reaches the power of personality? Personality predictors of terminal decline in well-being. Journal of Personality and Social Psychology. https://doi.org/10.1037/pspp0000184.

Myers, D. G., \& Diener, E. (1995). Who is happy? Psychological Science, 6, 10-19.

Myrseth, H., Olsen, O. K., Strand, L. Å., \& Borud, E. K. (2017). Gaming behavior among conscripts: The role of lower psychosocial well-being factors in explaining gaming addiction. Military Psychology, 29, 128-142.

Nazir, T., \& Pișkin, M. (2016). Phubbing: A technological invasion which connected the world but disconnected humans. International Journal of Indian Psychology, 3, 68-76.

Nishimura, T., \& Suzuki, T. (2016). Aspirations and life satisfaction in Japan: The big five personality makes clear. Personality and Individual Differences, 97, 300-305.

Ostovar, S., Allahyar, N., Aminpoor, H., Moafian, F., Nor, M., \& Griffiths, M. D. (2016). Internet addiction and its psychosocial risks (depression, anxiety, stress and loneliness) among Iranian adolescents and young adults: A structural equation model in a cross-sectional study. International Journal of Mental Health and Addiction, 14, 257-267.

Park, W. K. (2005). Mobile phone addiction. In R. Ling \& P. E. Pedersen (Eds.), Mobile communications (pp. 253-272). London: Springer.

Pavot, W., \& Diener, E. (1993). Review of satisfaction with life scale. Psychological Assessment, 5, $164-172$.

Pavot, W., Diener, E. D., Colvin, C. R., \& Sandvik, E. (1991). Further validation of the Satisfaction with Life Scale: Evidence for the cross-method convergence of well-being measures. Journal of Personality Assessment, 57, 149-161.

Preacher, K. J., \& Hayes, A. F. (2004). SPSS and SAS procedures for estimating indirect effects in simple mediation models. Behavior Research Methods, Instruments, \& Computers, 36, 717-731.

Preacher, K. J., \& Hayes, A. F. (2008). Asymptotic and resampling strategies for assessing and comparing indirect effects in multiple mediator models. Behavior Research Methods, 40, 879-891.

Preacher, K. J., \& Kelley, K. (2011). Effect size measures for mediation models: Quantitative strategies for communicating indirect effects. Psychological Methods, 16, 93-115.

Roberts, J. A., \& David, M. E. (2016). My life has become a major distraction from my cell phone: Partner phubbing and relationship satisfaction among romantic partners. Computers in Human Behavior, 54, 134 141.

Roberts, J. A., \& David, M. E. (2017). Put down your phone and listen to me: How boss phubbing undermines the psychological conditions necessary for employee engagement. Computers in Human Behavior, 75, 206217.

Rose, B. M., Holmbeck, G. N., Coakley, R. M., \& Franks, E. A. (2004). Mediator and moderator effects in developmental and behavioral pediatric research. Developmental and Behavioral Pediatrics, 25, 58-67.

Samaha, M., \& Hawi, N. S. (2016). Relationships among smartphone addiction, stress, academic performance, and satisfaction with life. Computers in Human Behavior, 57, 321-325.

Schimmack, U., Diener, E., \& Oishi, S. (2002). Life satisfaction is a momentary judgment and a stable personality characteristic: The use of chronically accessible and stable sources. Journal of Personality, 70, 345-385.

Șimșek, Ö. F., \& Koydemir, S. (2013). Linking metatraits of the big five to well-being and ill-being: Do basic psychological needs matter? Social Indicators Research, 112, 221-238.

Somer, O., \& Goldberg, L. R. (1999). The structure of Turkish trait-descriptive adjectives. Journal of Personality and Social Psychology, 76, 431-450.

Song, S. M., Park, B., Kim, J. E., Kim, J. E., \& Park, N. S. (2018). Examining the relationship between life satisfaction, smartphone addiction, and maternal parenting behavior: A South Korean example of mothers with infants. Child Indicators Research, 12, 1221-1241. https://doi.org/10.1007/s12187-018-9581-0. 
Suls, J., Green, P., \& Hillis, S. (1998). Emotional reactivity to everyday problems, affective inertia, and neuroticism. Personality and Social Psychology Bulletin, 24, 127-136.

Sun, J., Kaufman, S. B., \& Smillie, L. D. (2018). Unique associations between big five personality aspects and multiple dimensions of well-being. Journal of Personality, 86, 158-172.

Tabachnick, B. G., \& Fidell, L. S. (2007). Using multivariate statistics (5th ed.). New York: Pearson.

Turel, O., Serenko, A., \& Giles, P. (2011). Integrating technology addiction and use: An empirical investigation of online auction users. MIS Quarterly, 35, 1043-1062.

Ugur, N. G., \& Koc, T. (2015). Time for digital detox: misuse of mobile technology and phubbing. ProcediaSocial and Behavioral Sciences, 195, 1022-1031.

Weber, M., \& Huebner, E. S. (2015). Early adolescents' personality and life satisfaction: A closer look at global vs. domain-specific satisfaction. Personality and Individual Differences, 83, 31-36.

Weinstein, A., \& Lejoyeux, M. (2010). Internet addiction or excessive internet use. American Journal of Drug and Alcohol Abuse, 36, 277-283.

Yetim, Ü. (1991). Reliability and validity of Satisfaction with Life Scale in Turkish form. Paper presented at the 6th National Psychology Conference, Istanbul, Turkey.

Yetim, U. (2003). The impacts of individualism/collectivism, self-esteem and feeling of mastery on life satisfaction among the Turkish university students and academician. Social Indicators Research, 61, 297317.

Zhang, D., \& He, H. (2010). Personality traits and life satisfaction: A Chinese case study. Social Behavior and Personality, 38, 1119-1122.

Zhang, J. W., \& Howell, R. T. (2011). Do time perspectives predict unique variance in life satisfaction beyond personality traits? Personality and Individual Differences, 50, 1261-1266.

Publisher's Note Springer Nature remains neutral with regard to jurisdictional claims in published maps and institutional affiliations.

\section{Affiliations}

\section{Özkan Çikrikci ${ }^{1} \cdot$ Mark D. Griffiths $^{2} \cdot$ Evren Erzen $^{3}$}

1 Faculty of Education, Department of Educational Sciences, Ordu University, Ordu, Turkey

2 International Gaming Research Unit, Psychology Department, Nottingham Trent University, Nottingham, UK

3 Faculty of Education, Department of Elementary Education, Artvin Çoruh University, Artvin, Turkey 